\title{
KARAKTERISTIK SOSIAL YANG MEMPENGARUHI PERSEPSI DAN PERILAKU MASYARAKAT DALAM PENGELOLAAN HUTAN KEMASYARAKATAN
}

\author{
(Social Characteristics Affecting Perception and Community Behavior in Community Forest \\ Management)
}

Prihandini Tria Okta Viani, Christine Wulandari, Rahmat Safei, Hari Kaskoyo

Universitas Lampung, Jl. Prof. Soemantri Brojonegoro, No. 1 Bandar Lampung Telepon (0721) 701609

Kode pos 35145

Email : prihandinitraokta@gmail.com

\begin{abstract}
The management area of KPH VIII Batu Tegi which is a watershed of the Way Sekampung watershed included in the priority watershed category because most of the watershed areas have experienced changes in forest function. So that all forms of land management in the region can affect the quality and quantity of the Way Sekampung watershed, including a Social Forestry scheme with community empowerment. Community empowerment in KPH Unit VIII Batu Tegi needs to take into account to aspects of community characteristics that affect its perception and behavior in forest management. This study aimed to analyze the characteristics that influence people's perception and behavior in managing HKm. Respondents in this study were 71 members of the Mandiri Lestari Forest Farmers Group (Gapoktan) who have working areas in the Protected Forest area register 39 Kota Agung Utara. The analytical method used is non parametric statistical correlation Spearman Rank. The instrument used is a Likert scale. The results obtained indicate that the Social characteristics that have a real influence on people's perceptions are age. While the level of community behavior is not influenced by the observed characteristics of the respondents.
\end{abstract}

Keywords : behavior; characteristics; perception, community forest.

Abstrak

Wilayah pengelolaan Kesatuan Pengelolaan Hutan (KPH) VIII Batu Tegi merupakan daerah tangkapan air DAS Way Sekampung dan termasuk ke dalam kategori DAS yang di prioritaskan karena sebagian besar wilayah DAS sudah mengalami perubahan fungsi hutan. Segala bentuk pengelolaan lahan di wilayah tersebut dapat mempengaruhi kualitas serta kuantitas dari DAS Way Sekampung tersebut, termasuk di dalamnya terdapat program pemberdayaan masyarakat Perhutanan Sosial dengan skema Hutan Kemasyarakatan (Hkm). Hkm di KPH Unit VIII Batu Tegi perlu memperhatikan aspek karakteristik sosial masyarakat yang mempengaruhi persepsi dan perilakunya dalam pengelolaan hutan. Tujuan dilakukannya penelitian ini untuk menganalisis karakteristik sosial masyarakat yang mempengaruhi persepsi dan perilaku masyarakat dalam pengelolaan HKm. Responden pada penelitian ini yaitu bagian dari masyarakat anggota Gabungan Kelompok Tani Hutan (Gapoktan) Mandiri Lestari yang memiliki areal kerja di wilayah Hutan Lindung register 39 Kota Agung Utara sebanyak 71 orang yang dipilih secara acak sederhana dan dihitung menggunakan rumus Slovin. Metode analisis yang digunakan yaitu analisis statistik non parametrik korelasi Rank Spearman. Instrumen yang digunakan yaitu skala Likert. Hasil yang diperoleh menunjukkan bahwa karakteristik sosial yang memberikan pengaruh nyata pada persepsi masyarakat Gabungan Kelompok Tani Hutan Mandiri Lestari adalah usia, sedangkan tingkat perilaku masyarakat tidak dipengaruhi oleh karakteristik sosial masyarakat yang diamati

Keywords : Hutan Kemasyarakatan, Persepsi, Prilaku, karakteristik 


\section{PENDAHULUAN}

Perhutanan sosial merupakan salah satu kebijakan pemberdayaan masyarakat sekitar yang dikeluarkan oleh pemerintah terkait dengan penyelesaian konflik dan untuk memaksimalkan aliran manfaat hutan dari aspek social, ekonomi dan ekologi (Novayanti et al., 2017 dan Laksemi et al, 2019). Kegiatan Perhutanan Sosial diperlukan untuk mengurangi kemiskinan, pengangguran dan ketimpangan pengelolaan atau pemanfaatan kawasan hutan. Kegiatan tersebut dilakukan melalui pemberian akses legal kepada masyarakat setempat antara lain melalui program Hutan Kemasyarakatan (HKm) di lahan hutan negara (Kementerian Lingkungan Hidup dan Kehutanan, 2016). Program Hutan Kemasyarakatan (HKm) merupakan salah satu upaya dalam melestarikan kawasan hutan dan memberikan manfaat pada masyarakat (Puspita et al, 2020)

Tujuan program $\mathrm{HKm}$ untuk meningkatkan kesejahteraan masyarakat melalui pemanfaatan sumber daya hutan secara optimal, adil dan berkelanjutan dengan tetap menjaga kelestarian fungsi hutannya (Kaskoyo et al,. 2014). HKm yang terletak di Pekon Datar Lebuay, Kecamatan Air Naningan, Kabupaten Tanggamus ini termasuk dalam wilayah pengelolaan KPH VIII Batu Tegi Register 39, Resort Way Sekampung. Adanya HKm ini memiliki potensi pemanfaatan kawasan, pemanfaatan jasa lingkungan dan potensi pemungutan hasil Hutan bukan kayu. Pemanfaatan potensi tersebut perlu perlindungan lebih dengan cara melibatkan pemberdayaan masyarakat dalam $\mathrm{HKm}$ sebagai upaya meningkatkan kemampuan dan kemandirian masyarakat yang menggantungkan hidupnya pada hutan agar dapat memanfaatkan sumber daya hutan secara optimal (Sanudin, et al., 2016). Sejalan dengan yang dikemukakan oleh Kaskoyo et al, (2014) bahwa pemberdayaan masyarakat baik individu maupun kelompok harus dibangun untuk menciptakan pengelolaan hutan secara mandiri dan lestari serta berimplikasi pada implementasi program HKm yang baik.

Penerapan skema pemberdayaan masyarakat dalam $\mathrm{Hkm}$ harus memperhatikan karakteristik sosial masyarakat yang menjadi subyek di daerah tersebut (Kasim dan Hussen, 2019). Beberapa karakteristik sosial yang perlu diperhatikan diantaranya yaitu persepsi dan perilaku masyarakat terhadap keberadaan $\mathrm{Hkm}$ tersebut. Wulandari dan Inou (2018) menyatakan bahwa persepsi merupakan suatu proses yang memberikan kesadaran bagi seseorang tentang suatu objek diluar dirinya melalui panca indra. Perilaku menurut Surati (2015) merupakan perkataan serta perbuatan seseorang yang sifatnya dapat diamati, dicatat serta digambarkan baik oleh orang itu sendiri maupun oleh orang lain. Persepsi merupakan dasar pembentukan perilaku (Tampubolon, 2018) sehingga variabel persepsi dan perilaku masyarakat penting untuk diketahui 
sebagai acuan penerapan pemberdayaan masyarakat dalam skema $\mathrm{HKm}$ yang efektif dan diharapkan mampu menjadi solusi penyelesaian permasalahan yang terjadi. Irawan et al, (2017) menyatakan hal yang sama dalam penelitiannya bahwa dalam penerapan skema pemberdayaan masyarakat di perlu memperhatikan persepsi dan perilaku masyarakat

Persepsi ini dapat diwujudkan dalam bentuk program yang sinergis antar elemen baik pemerintah maupun masyarakat terkait untuk sama-sama meningkatkan optimalisasi pemanfaatan kawasan hutan dalam wilayah kelola KPH VIII Batutegi yang memberi manfaat ekonomi baik bagi masyarakat maupun pemerintah serta manfaat ekologi. Akan tetapi hingga saat ini persepsi yang diharapkan belum terbangun dengan baik, salah satu bukti adalah dokumen kesepakatan antara gubernur dan sepuluh bupati atau walikota se Provinsi Lampung yang ditandatangani pada tahun 2010 untuk menyelamatkan cacthment area Batutegi tidak ditindaklanjuti oleh pihak manapun. Ketika pada tahun 2012 dokumen tersebut diungkap kembali untuk menggugah para pihak terhadap komitmen yang sudah dibuat, ternyata masih juga belum mampu memberi motivasi mereka untuk bergerak menyusun program sinergis yang diharapkan.

Tujuan dilakukannya penelitian ini untuk menganalisis karakteristik sosial yang mempengaruhi persepsi dan perilaku masyarakat dalam pengelolaan $\mathrm{HKm}$. Ditinjau darisegi pengelolaan,
HKm di Desa Datar Lebuay masih jauh dari kata baik, sehingga program HKm belum dapat diimplementasikan guna menerapkan pengelolaan hutan berbasis masyarakat yang mandiri dan lestari. Penelitian mengenai persepsi dan perilaku masyarakat terhadap keberadaan Hkm di KPH VIII Batu Tegi khususnya pada Resort Way Sekampung belum pernah dilakukan. Sejauh ini, penelitian yang dilakukan di $\mathrm{KPH}$ VIII Batu Tegi terkait pembentukan KPHL Batu Tegi dari sisi masyarakat dan LSM (Rohana et al., 2016). Menurut Masria et al (2015), variabel persepsi berpengaruh terhadap perilaku. Irawan et al, (2017) mengemukakan bahwa persepsi dan perilaku dipengaruhi oleh karakteristik sosial masyarakat.

Hasil penelitian ini diharapkan dapat menjadi dasar dalam merumuskan program pemberdayaan masyarakat yang efektif dan sebagai solusi pengelolaan $\mathrm{HKm}$ di Desa Datar Lebuay, Kecamatan Air Naningan dari aspek persepsi masyarakat terhadap pengelolaan hutan. Oleh sebab itu, penelitian terkait persepsi dan perilaku masyarakat terhadap keberadaan hutan kemasyarakatan di Provinsi Lampung khususnya di Pekon Datar Lebuay menjadi sangat penting untuk dilakukan.

\section{METODE PENELITIAN}

Penelitian ini dilakukan di Pekon Datar Lebuay, Kecamatan Air Naningan, Kabupaten Tanggamus. Peta lokasi penelitian ditunjukkan pada Gambar 1. 


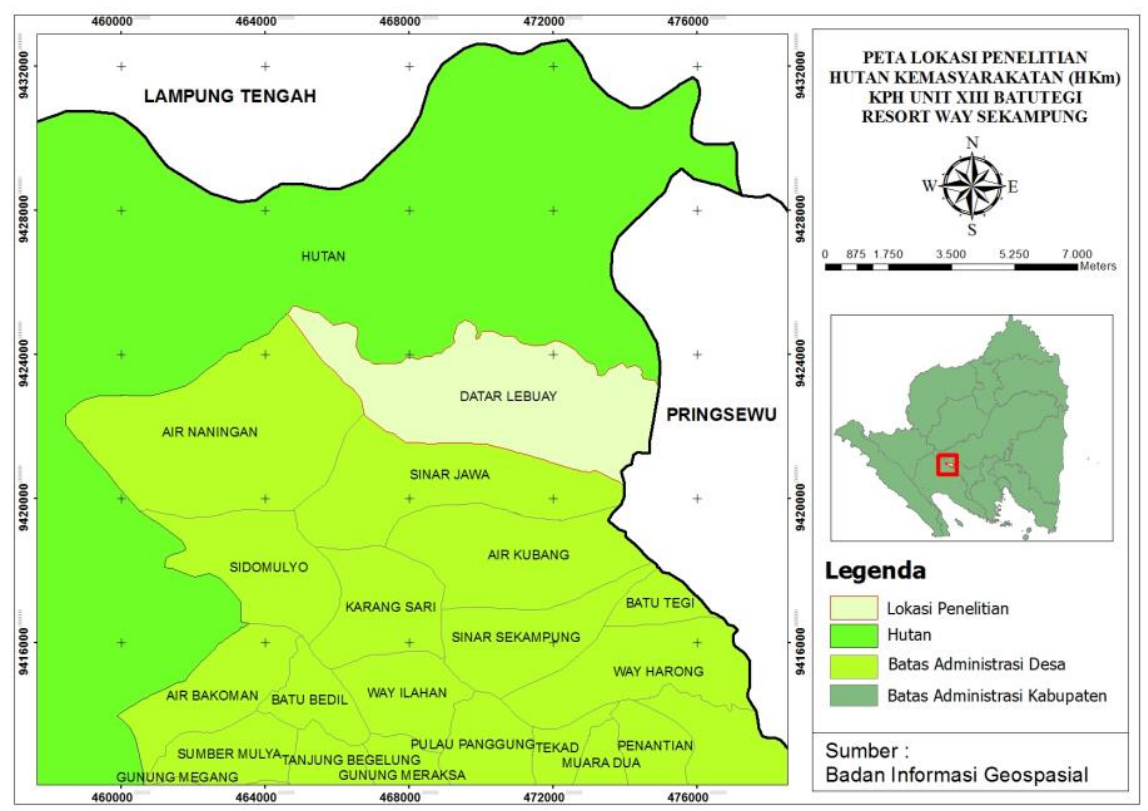

Gambar 1. Peta Lokasi Penelitian (Research Location Map)

Lokasi penelitian termasuk dalam areal kerja KPH Unit VIII Batu Tegi Resort Way Sekampung. Pengambilan data dilakukan pada bulan Januari 2020. Alat yang digunakan dalam penelitian ini berupa instrumen kuesioner, kamera serta alat tulis. Objek penelitian adalah masyarakat anggota kelompok tani hutan Mandiri Lestari yang aktif dalam pengelolaan hutan.

Data yang dikumpulkan dikategorikan menjadi 2 jenis data yaitu data primer dan data sekunder. Data primer berupa data umum anggota kelompok tani yang meliputi nama, usia, jenis kelamin, pendidikan terakhir, lama menetap, pekerjaan pokok, pendapatan perbulan yang diperoleh dari observasi lapang dan menggunakan panduan kuisioner semi terstruktur. Data sekunder meliputi keadaan umum penelitian antara lain: letak, keadaan fisik lingkungan, dan sosial ekonomi masyarakat serta keadaan lahan, peta lokasi dan peta lahan garapan petani.
Data sekunder diperoleh dari monografi Pekon Datar Lebuay dan dari KPH VIII Batu Tegi serta Dinas Kehutanan Provinsi Lampung. Responden penelitian dipilih secara acak sederhana sejumlah 71 orang yang dihitung menggunakan rumus Slovin.

Hasil penelitian ini kemudian di analisis menggunakan metode analisis deskriptif dan statistika non parametrik korelasi Rank Spearman. Metode analisis deskriptif digunakan untuk menjawab faktor apa saja yang mempengaruhi suatu persepsi. Instrumen yang digunakan yaitu skala Likert. Hasil data atau skor yang diperoleh dari kuisioner mengenai sistem pengelolaan lahan yang dilakukan oleh anggota kelompok Tani disajikan dalam bentuk tabel, kemudian dilakukan pengkategorian dengan menggunakan skala pengukuran.

Tingkat pengukuran skala dalam penelitian ini menggunakan interval sesuai dengan Sugiyono (2014) yang dapat dilihat pada Tabel 1. 
Tabel 1. Kriteria yang Digunakan untuk Mengetahui Kategori Persepsi dan Perilaku Masyarakat (The Criteria Used to Determine the Categories of Perception and Behavior)

\begin{tabular}{cccc}
\hline Variabel & Kategori & Skor & Persentase \\
\hline Persepsi terhadap pengelolaan & Sangat Baik (SB) & 4 & $76 \%-100 \%$ \\
HKm & Baik (B) & 3 & $51 \%-75 \%$ \\
& Tidak Baik (TB) & 2 & $26 \%-50 \%$ \\
& Sangat Tidak Baik (STB) & 1 & $0 \%-25 \%$ \\
\hline Perilaku terhadap pengelolaan & Sangat Sesuai (SS) & 4 & $76 \%-100 \%$ \\
HKm & Sesuai (S) & 3 & $51 \%-75 \%$ \\
& Tidak Sesuai (TS) & 2 & $26 \%-50 \%$ \\
& Sangat Tidak Sesuai (STS) & 1 & $0 \%-25 \%$ \\
\hline
\end{tabular}

Pengkategorian ini sebagai cara untuk menentukan nilai berbentuk interval berdasarkan data sampel, dimana nilai tersebut sebagai penggganti dari nilai parameter yang tidak diketahui. Respon netral sengaja dihilangkan sehingga responden dapat menunjukkan sikap maupun pendapatnya terhadap pertanyaan yang diajukan pada kuesioner. Hal ini dilakukan untuk meminimalisir kesalahan kecenderungan menengah dalam metode skala likert.

Data interval tersebut dapat dianalisis dengan menghitung persentase jawaban angket pada tiap item. Setelah pengolahan data selesai, langkah selanjutnya adalah analisis data. Analisis data pada penelitian ini menggunakan metode statistik deskriptif, yaitu analisis yang mencoba menjelaskan dan menggambarkan pelaksanaan, partisipasi serta kendala yang dihadapi oleh masyarakat dalam pengelolaan $\mathrm{HKm}$ berdasarkan data yang ada (Maswar, 2017). Data dalam penelitian ini ditampilkan melalui tabeltabel frekuensi yang disajikan dalam persentase.

Wawancara dilakukan kepada anggota Gapoktan Mandiri Lestari menggunakan instrumen kuesioner yang
Skala Likert. Instrumen skala Likert digunakan untuk mengukur sikap, pendapat dan persepsi seseorang atau sekelompok orang tentang suatu fenomena sosial (Sugiyono, 2015). Instrumen ini membagi variabel yang akan diukur menjadi indikator variabel yang bernilai mulai dari positif hingga negatif. Indikator tersebut dijadikan sebagai titik tolak untuk menyusun item instrumen yang dapat berupa pertanyaan atau pernyataan. Indikator yang digunakan pada penelitian ini akan dibagi menjadi empat

Indikator yang menjadi pertanyaan dalam instrumen kuesioner mencakup 34 pertanyaan untuk mengetahui persepsi dan 36 pertanyaan untuk mengetahui perilaku masyarakat terhadap pengelolaan $\mathrm{Hkm}$. Pertanyaan tersebut berkaitan dengan pengelolaan $\mathrm{HKm}$ yang dilakukan oleh anggota Gapoktan Mandiri Lestari mulai dari pengetahuan tentang kondisi sosial ekonomi masyarakat, dan kegiatan pengelolaan mulai dari perencanaan, penerapan program, penilaian program dan pemanfaatan hasil hutan bukan kayu di areal HKm. Indikator yang digunakan untuk menguji tingkat hubungan terhadap variabel persepsi dan perilaku disajikan pada Tabel 2. 
Tabel 2. Indikator-Indikator yang Digunakan untuk Mengetahui Persepsi dan Perilaku Masyarakat dalam Pengelolaan Hutan Kemasyarakatan (The Indicators Used to Determine the Perception and Behavior of Society Towards the Community Forest Management)

\begin{tabular}{cll}
\hline Variabel & & \multicolumn{1}{c}{ Indikator } \\
\hline Persepsi masyarakat & 1. & Pengetahuan tentang kondisi sosial ekonomi masyarakat \\
& 2. & Pengetahuan tentang pemanfaatan HKm \\
& 3. & Pengetahuan tentang perencanaan program HKm \\
& 4. & Pengetahuan tentang penerapan program HKm \\
& 5. & Pengetahuan tentang evaluasi pengelolaan HKm \\
\hline Perilaku masyarakat & 1. & Kegiatan pengolahan lahan dalam kawasan hutan berkaitan dengan \\
& & kondisi sosial ekonomi masyarakat \\
& 2. Kegiatan pengolahan lahan berkaitan dengan pemanfaatan HKm \\
& 3. Kegiatan pengolahan lahan berkaitan dengan perencanaan program HKm \\
& 4. Kegiatan pengolahan lahan berkaitan dengan penerapan program HKm \\
5. Kegiatan pengolahan lahan berkaitan dengan evaluasi pengelolaan HKm
\end{tabular}

\section{HASIL DAN PEMBAHASAN Kondisi Umum Penelitian \\ Wilayah kerja KPH Unit VIII Batu} Tegi meliputi sebagian kawasan Hutan Lindung Register 39 Kota Agung Utara, sebagian Kawasan Hutan Lindung Register 22 Way Waya dan sebagian kawasan Hutan Lindung Register 32 Bukit Rindingan. Letak geografis KPH Unit VIII Batu Tegi berada pada $104^{\circ} 27^{\prime}-104^{\circ} 54^{\prime}$ BT dan $5^{\circ} 5^{\prime}-5^{\circ} 22^{\prime}$ LS. Areal kelola KPH Unit VIII Batu Tegi seluas 58,174 Ha. Blok inti dalam wilayah kelola KPH Batu Tegi seluas 10,827 Ha yang merupakan Catchment area bendungan Batu Tegi. Catchment area bendungan batu tegi menjadi salah satu area penting di Provinsi Lampung karena wilayah tersebut termasuk ke dalam kategori DAS yang di prioritaskan karena sebagian besar wilayah DAS sudah mengalami perubahan fungsi hutan menjadi lahan pertanian.

Wilayah kelola KPH Unit VIII Batu Tegi dibagi menjadi 6 wilayah resort. Enam resort tersebut adalah Resort Way Waya, Resort Banjaran,
Resort Batulima, Resort Datar Setuju, Resort Way Sekampung dan Resort Ulu Semong. KPH Unit VIII Batu Tegi berhimpitan dengan sekitar 20 wilayah desa di tiga kecamatan di Kabupaten Tanggamus dan satu desa di Kabupaten Pringsewu, satu desa di Kabupaten Lampung Barat, dan dua desa di Kabupaten Lampung Tengah.

Berdasarkan data yang dihimpun dalam Rencana Pengelolaan Hutan Jangka Panjang (RPHJP) KPH Batu Tegi 2014-2023 diketahui bahwa penutupan vegetasi wilayah kelola KPH Unit VIII Batu Tegi didominasi dengan vegetasi non hutan, yaitu sebanyak $76,49 \%$. Di dalamnya telah ada petani penggarap baik yang tergabung dalam kelompok-kelompok tani dan memiliki izin usaha HKm maupun yang belum. Menurut Nurrani dan Tabba (2013), ketergantungan masyarakat terhadap kawasan hutan cukup tinggi karena sebagian besar menjadikan kawasan hutan sebagai tempat mencari nafkah akan tetapi mereka memiliki persepsi yang cukup baik tentang kawasan hutan. 
Dengan kondisi tersebut, maka potensi terbesar di wilayah kelola KPH Unit VIII Batu Tegi adalah komoditi hasil petani penggarap berupa kopi, lada, kakao, karet, kemiri, pala, durian dll.

Resort Way Sekampung memiliki luas 14,422 $\mathrm{Ha}$ dan berada di Kabupaten Tanggamus dalam kawasan hutan lindung Register 39 Kota Agung Utara. Kondisi tutupan vegetasi mayoritas berupa hutan sekunder, semak belukar dan lahan pertanian campuran. Sebagian areal di resort ini seluas merupakan blok inti, karena menjadi catchment area Way Sekampung. Di wilayah Resort Way Sekampung terdapat 2 Gapoktan HKm yaitu Gapoktan HKm Mandiri Lestari dan Gapoktan Wana Tani Lestari.

1. Gapoktan Mandiri Lestari berada di Register 39 Kota Agung Utara Kab. Pringsewu. Jumlah anggota Gapoktan Wana Lestari sebanyak \pm 235 orang dengan luas areal yang sudah terbit IUPHKM $\pm 1.401,80$ Ha. SK Menhut No. 751/MenhutII/2009 tanggal 2 November 2009 dan SK Bupati No. B.262/39/12/2009 tanggal 11 Desember 2009.

2. Gapoktan Wana Tani Lestari memiliki jumlah anggota 423 orang, luas areal yang diusulkan $\pm 3.200 \mathrm{Ha}$. Proses pengusulan $\mathrm{HKm}$ saat ini masih dalam tahap penyusunan proposal dan pembuatan peta usulan dengan difasilitasi oleh KPH Unit VIII Batutegi.

\section{Gapoktan Mandiri Lestari}

Gapoktan yang menjadi objek dalam penelitian ini yaitu Gapoktan
Mandiri Lestari. Kelompok HKm ini berdiri berdasarkan SK Menhut No. 751/Menhut-II/2009 tanggal 2 November 2009 dan SK Bupati No. B.262/39/12/2009 tanggal 11 Desember 2009. Jumlah anggota 235 orang dengan luas areal 1.401,80 Ha. Gabungan Kelompok tani HKm Mandiri Lestari terbagi menjadi 10 sub kelompok tani yang masing-masing mempunyai susunan kepengurusan antara lain : Ketua, Sekretaris, bendahara dan seksiseksi kerja. Secara geografis areal kerja gapoktan HKm Mandiri Lestari terletak di wilayah hutan lindung register 39 Kota Agung Utara sebelah Utara yang saat ini telah terbagi menjadi 2 zona antara lain zona budidaya dan zona lindung (KPH VIII Batu Tegi, 2014).

\section{Persepsi dan Perilaku Masyarakat}

Persepsi merupakan suatu proses individu dalam mengenali objek atau suatu fenomena melalui panca indera yang sifatnya objektif. Menurut Utami (2016) dan Dewi et al (2019), persepsi adalah proses psikologi yang dialami seseorang untuk melakukan suatu hal atau tidak melakukan suatu hal didasari oleh stimulan tertentu. Persepsi juga dapat berarti pengalaman untuk mengartikan makna dari seorang atau objek yang dilihatnya. Dewinta et al (2018) menyatakan bahwa setiap orang mempunyai kecenderungan melihat suatu objek atau fenomena yang sama dengan cara yang berbeda. Menurut Tadesse dan Taketay (2017) perbedaan cara pandang tersebut dapat dipengaruhi oleh banyak faktor. Faktor tersebut diantaranya yaitu pengetahuan, pengalaman dan sudut pandang 
darimana individu tersebut melihat (Putri et al, 2019).

Berdasarkan hasil survey diketahui bahwa secara umum masyarakat memiliki presepsi yang baik terhadap kawasan hutan. Walaupun demikian, kenyataan di lapangan ditemukan bahwa sebagian masyarakat Anggota Gapoktan Mandiri Lestari tidak mengikuti peraturan yang telah ditetapkan dalam pengelolaan $\mathrm{HKm}$. perilaku masyarakat yang tidak tertib aturan pengelolaan $\mathrm{Hkm}$ adalah terjadinya jual beli lahan yang dilakukan antar anggota Gapoktan. Kegiatan jual beli lahan ini terjadi akibat kurangnya pengawasan pemerintah terhadap pengelolaan $\mathrm{Hkm}$.

Menurut Kristin et al (2018), interaksi masyarakat dalam pemanfaatan hutan umumnya bertujuan untuk memenuhi kebutuhan konsumsi keluarga dan juga untuk diperjualbelikan. Pada Hutan Lindung, pemanfaatan hasil hutan terbatas pada hasil hutan bukan kayu dan jasa lingkunga, Kayu bakar merupakan hasil hutan yang pemanfaatannya terbatas untuk konsumsi sendiri dan tidak boleh diperjuabelikan sedangkan hasil hutan bukan kayu dapat diperjualbelikan dan digunakan sebagai sumber penghasilan masyarakat.

Hasil yang diperoleh menunjukkan bahwa persepsi masyarakat Gabungan Kelompok Tani Hutan Mandiri Lestari berada pada kategori sangat baik yaitu sebesar $75,435 \%$. Persepsi yang baik ditunjukkan dengan Perilaku masyarakat berada pada kategori sesuai yaitu sebesar 53,56\%. Persepsi yang baik ditunjukkan dengan bagaimana masyarakat memahami bahwa $\mathrm{Hkm}$ dapat memberikan manfaat ekologi, ekonomi dan sosial budaya yang baik bagi masyarakat selagi mereka mengelola hutan dengan baik. Selain itu, persepsi yang baik juga ditunjukan dengan pemahaman masyarakat tentang adanya Gapoktan dapat membantu menyelesaikan masalah terkait pengelolaan $\mathrm{Hkm}$.

Perilaku yang positif ditunjukkan dengan anggota Gapoktan Mandiri Lestari yang menaati peraturan dalam pengelolaan $\mathrm{Hkm}$ seperti jenis tanaman yang boleh ditanam dan peraturan tentang larangan menebang kayu. Namun, terdapat pula perilaku yang tidak positif yang ditunjukkan dengan terdapatnya jual beli lahan garapan yang dilakukan oleh anggota Gapoktan.

Uji hipotesis terhadap korelasi antara persepsi dengan perilaku masyarakat dengan tingkat signifikasi ( $\alpha$ ) sebesar 0,05 diperoleh hasil bahwa terdapat hubungan antara persepsi dan perilaku masyarakat di dalam pengelolaan hutan dengan korelasi sebesar 0,2719. Pengamatan langsung di lapangan menunjukkan bahwa secara umum, masyarakat memiliki persepsi yang baik terhadap pengelolaan Hkm. Hal ini dibuktikan dengan aturan pengelolaan $\mathrm{Hkm}$ yang dilaksanakan dengan baik. Aturan ini meliputi diharuskannya anggota $\mathrm{Hkm}$ untuk menanam jenis tanaman berkayu dan jenis Multiple Purpose Trees Species (MPTS) di areal kerja.

Jenis tanaman yang terdapat di lokasi penelitian terdiri dari jenis 
tanaman pokok, tanaman sisipan dan tanaman sisipan ikutan. Jenis tanaman pokok yang diusahakan oleh anggota Gapoktan Mandiri lestari adalah kopi (Coffea). Jenis tanaman sisipan berupa golongan Multi Purpose Tree Species (MPTS) antara lain jengkol (Pithecellobium lobatum), pete (Parkia speciosa), durian (Durio Zibethinus), manggis (Garcinia mangostana), rambutan (Nephelium lappaceum), cempedak (Artocarpus integer), mangga (Mangifera indica) serta jenis tanaman sisipan berupa lada (Piper nigrum).

Terdapat pula jenis pohon kayukayuan yang sudah sejak dulu berada di areal $\mathrm{HKm}$ seperti randu (Ceiba pentandra), mahoni (Swietenia mahagoni), wareng (Gmelina arborea). Pohon berkayu ini wajib dipelihara oleh masing-masing anggota $\mathrm{HKm}$ sesuai dengan aturan main yang telah disepakati oleh anggota Gapoktan. Sebagian besar anggota menyadari pentingnya manfaat pohon berkayu tersebut, diantaranya yaitu sebagai penghasil oksigen serta berperan dalam konservasi tanah dan air.

\section{Hubungan karakteristik reponden dengan persepsi dan perilaku}

Program pemberdayaan masyarakat menjadi suatu hal yang penting dalam menunjang pengelolaan hutan yang mandiri dan lestari. Dalam pelaksanaanya, program pemberdayaan masyarakat tidak lepas dari faktorfaktor yang mempengaruhi keberhasilan program tersebut. Faktor tersebut diantaranya berasal dari dalam maupun dari luar. Irawan et al (2017) menyatakan bahwa karakteristik sosial masyarakat merupakan faktor kunci dalam pelaksanaan program pengelolaan hutan.

Irawan (2017) menyatakan bahwa kegagalan program pemberdayaan masyarakat sebagian besar disebabkan oleh kendala yang berasal dari pengelolaan hutan. Persepsi dan perilaku individu adalah salah satu bentuk dari karakteristik sosial yang banyak dipertimbangkan untuk penerapan skema pemberdayaan masyarakat. Faktor-faktor tersebut menjadikan persepsi individu berbeda satu sama lain dan akan berpengaruh pada individu dalam mempersepsi suatu objek, stimulus, meskipun objek tersebut benar-benar sama.

Persepsi seseorang atau kelompok dapat jauh berbeda dengan persepsi orang atau kelompok lain sekalipun situasinya sama. Perbedaan persepsi dapat ditelusuri pada adanya perbedaanperbedaan individu, perbedaan perbedaan dalam kepribadian, perbedaan dalam sikap atau perbedaan dalam motivasi. Pada dasarnya proses terbentuknya persepsi ini terjadi dalam diri seseorang, namun persepsi juga dipengaruhi oleh pengalaman, proses belajar, dan pengetahuannya. Tingkat persepsi dan perilaku masyarakat terhadap keberadaan hutan merupakan informasi penting yang dapat dijadikan dasar bahan pertimbangan dalam pelaksanaan program pemberdayaan masyarakat. Hasil yang diperoleh dari uji korelasi terhadap persepsi dan perilaku ditunjukkan pada Tabel 3. 
Tabel 3. Korelasi Karakteristik Sosial Masyarakat dengan Persepsi dan Perilaku Masyarakat (The Corelation of Social Characteristics with Perception and Behaviour of Communities )

\begin{tabular}{lcc}
\hline \multirow{2}{*}{ Karakteristik sosial masyarakat } & \multicolumn{2}{c}{ Koefisien korelasi } \\
\cline { 2 - 3 } & Persepsi & perilaku \\
\hline Usia & $-0,277^{*}$ & $-0,218$ \\
Tingkat pendapatan bersumber dari dalam kawasan & 0,003 & 0,40 \\
Luas lahan garapan & $-0,124$ & $-0,158$ \\
Jarak kebun ke jalan akses & $-0,060$ & 0,028 \\
Jarak kebun ke kampung & 0,010 & 0,051 \\
\hline
\end{tabular}

Keterangan :

*korelasi signifikan pada $\alpha=0,05 ; * *$ korelasi signifikan pada $\alpha=0,01$

Sumber : Data prime

Berdasarkan hasil uji korelasi antara karakteristik sosial masyarakat dengan persepsi dan perilaku dapat diketahui bahwa karakteristik sosial yang memberikan pengaruh nyata pada persepsi masyarakat adalah Usia. Usia seseorang memiliki korelasi positif terhadap persepsinya. Berkorelasi positif artinya hubungan antara dua variabel berjalan searah. Apabila variabel usia naik, maka variabel persepsi juga naik dan apabila variabel usia turun maka variabel persepsi juga turun. Hal ini sejalan dengan yang dikemukakan oleh Purnamaningsih dan Ariyanto (2016) bahwa usia seseorang memiliki pengaruh positif dan signifikan terhadap persepsinya. Sebanyak 99\% anggota Gapoktan Mandiri Lestari berada pada rentang usia produktif. Putri dan Setiawina (2013) menyatakan bahwa umur produktif seseorang berkisar antara 15-64 tahun.

Kisaran umur ini merupakan umur ideal bagi para pekerja. Secara umum, dimasa produktif pendapatan seseorang akan meningkat seiring dengan bertambahnya umur dan pekerjaan yang dilakukan (Amelia et al, 2019). Ketika seseorang sudah melewati masa produktif, maka kekuatan fisik seseorang untuk melakukan pekerjaan akan menurun. Ditinjau dari aspek usia, masyarakat anggota Gapoktan Mandiri Lestari merupakan sumberdaya manusia yang potensial untuk dikembangkan dan ditingkatkan kemampuannya dalam pengelolaan $\mathrm{Hkm}$.

Hasil penelitian menunjukkan bahwa tidak terdapat hubungan yang signifikan antara karakteristik sosial masyarakat yang diamati dengan perilakunya. Wawancara dan hasil observasi di lapangan menunjukkan bahwa dengan adanya persepsi masyarakat anggota Gapoktan yang baik terhadap keberadaan hutan tidak menjamin terjadinya perilaku yang positif.

Hasil ini didukung oleh Masria et al. (2015) yang menyatakan bahwa persepsi masyarakat Desa Labuan Toposo Kecamatan Labuan Kabupaten Donggala terhadap hutan di sekitar wilayah Desa Labuan Toposo tergolong baik, namun sekalipun persepsi masyarakat baik terhadap hutan tidak menjamin terjadinya sikap yang positif, malah sebaliknya negatif. Kasus serupa juga dinyatakan oleh Irawan et al (2017) bahwa persepsi masyarakat yang baik terhadap kawasan KPHP Model Poigar yang terletak di 
Kabupaten Bolaang Mongondow dan Kabupaten Minahasa Selatan, Sulawesi Utara tidak memberikan pengaruh secara signifikan terhadap perilaku masyarakat.

\section{KESIMPULAN}

Kesimpulan yang diperoleh dari penelitian ini antara lain.

1. Persepsi masyarakat yang baik terhadap pengelolaan $\mathrm{HKm}$ memberikan pengaruh yang signifikan terhadap perilakunya.

2. Karakteristik sosial masyarakat yang memberikan pengaruh nyata pada persepsi masyarakat adalah usia, sedangkan pada perilaku masyarakat tidak dipengaruhi oleh karakteristik sosial yang diamati

\section{SARAN}

Penerapan program pemberdayaan masyarakat melalui skema $\mathrm{Hkm}$ pada register 39 Kota Agung Utara perlu memperhatikan aspek usia produktif yaitu pada rentang usia muda. Meningkatkan peran penyuluhan kepada anggota yang muda dan kegiatan tingkat lanjut seperti pengadaan pelatihan pembuatan bibit yang baik, budidaya secara agroforestry, penanaman atau pengayaan tanaman dibawah tegakan, pengolahan hasil hutan bukan kayu dapat dilakukan agar terciptanya persepsi yang baik terhadap pengelolaan hutan.

Perlu dilakukan penelitian lebih lanjut agar dapat diketahui mengapa karakteristik sosial masyarakat tidak memberikan pengaruh signifikan terhadap perilaku masyarakat

Perlu dilakukan penelitian lebih lanjut agar dapat diketahui program pemberdayaan masyarakat yang efektif untuk diterapkan dan sebagai solusi pengelolaan $\mathrm{HKm}$ di Register 39 Kota
Agung Utara dari aspek persepsi masyarakat terhadap pengelolaan hutan

UCAPAN TERIMA KASIH

Terimakasih kepada Kepala KPH Unit VIII Batu Tegi serta para staf yang telah banyak memberikan bantuan selama pelaksanaan kegiatan penelitian ini hingga selesainya penulisan naskah.

\section{DAFTAR PUSTAKA}

Amelia, N. R., Kartodihardjo, H., \& Sundawati, L. (2019). Peran modal sosial masyarakat penambang emas dalam mempertahankan tambang ilegal di Taman Hutan Raya Sulawesi Tengah. Jurnal Sylva Lestari. 7(3): 255-266.

Dewi, B. S., Kamaluddin, A., \& Gdemakarti, Y. (2019). Persepsi masyarakat terhadap pengembangan penangkaran rusa (Cervus sp) di Kota Bandar Bampung. Jurnal Sylva Lestari. 7(2): 244-254.

Dewinta, R. A., Nurmayasari, I., \& Sadar, S. (2018). Persepsi anggota KPPH terhadap pengelolaan Tahura di Kelurahan Sumber Agung Kecamatan Kemiling Kota Landar lampung. JIIA, 6(3): 334-340.

Heryatna, D., Zainal, S., \& Husni, H. (2015). Persepsi masyarakat terhadap keberadaan hutan kemasyarakatan di Desa Merangun Kec. Nanga Taman Kab. Sekandau. Jurnal Hutan Lestari, 4(1):58-64.

Irawan, A., Iwanuddin, J., Halawne, E., \& Ekawati, S. (2017). Analisis persepsi dan perilaku masyarakat terhadap keberadaan kawasan KPHP Model Poigar (perception and behavior analysis of community to the existence of Poigar PFMU Model). Jurnal Penelitian Sosial Dan Ekonomi Kehutanan, 14(1): 71-82. 
Kasim, M. M., \& Hussen, U. N. (2019). Local communities attitude toward community based forest management: the case of Jello Forest, West Hararghe Zone , Oromia Regional State, Ethiopia. Journal of Environmental Protection, 8(4): 78-86.

Kaskoyo, H., Mohammed, J. A., \& Inoue, M. (2014). Present state ff community forestry (hutan kemasyarakatan $/ \mathrm{hkm}$ ) program in a protection forest and its challenges: case study in Lampung Province, Indonesia. Journal of Forest Science, 30(1): 15-29.

Kristin, Y., Qurniati, R., \& Kaskoyo, H. (2018). Interaksi masyarakat sekitar hutan terhadap pemanfaatan lahan Taman Hutan. Jurnal Sylva Lestari. 6(3): 1-8.

Laksemi, N. P. S. T., Sulistyawati, E., \& Mulyaningrum. (2019). Perhutanan sosial berkelanjutan di Provinsi Bali (studi kasus di hutan Desa Wanagiri). Jurnal Sylva Lestari. 7(2): 150-163.

Masria, Golar, \& Ihsan, M. (2015). Persepsi dan sikap masyarakat lokal terhadap hutan di Desa Labuan Toposo Kecamatan Kabuan Kabupaten Donggala. Warta Rimba. 3(2):57-64.

Maswar. (2017). Analisis statistik deskriptif nilai uas ekonomitrika mahasiswa dengan program SPSS 23 \& eviews 8.1. JIIA, 1(2): 273292.

Novayanti, D., Banuwa, I. S., Safe'i, R., Wulandari, C., \& Febryano, I. G. (2017). Analisis faktor-faktor yang mempengaruhi persepsi masyarakat dalam pembangunan hutan tanaman rakyat pada KPH Gedong Wani.
Jurnal Hutan dan Masyarakat, 9(2): 61-74.

Nurrani, L., \& Tabba, S. (2013). Persepsi dan tingkat ketergantungan masyarakat terhadap sumberdaya alam Taman Nasional Aketajawe Lolobata di Provinsi Maluku Utara. Jurnal Penelitian Sosial dan Ekonomi Kehutanan. 10(1): 61 - 73.

Purnamaningsih, N. K. A., \& Ariyanto, D. (2016). Pengaruh gender, usia, tingkat pendidikan, dan status sosial ekonomi terhadap persepsi etis mahasiswa akuntansi. Jurnal Akuntansi Universitas Udayana. 17(2): 996-1029.

Puspita, T. N., Qurniati, R., \& Febryano, I. G. (2020). Modal sosial masyarakat pengelola hutan kemasyarakatan di KPH Batutegi. Jurnal Sylva Lestari, 8 (1): 54-64.

Putri, A. D., \& Setiawina, N. D. (2013). Pengaruh umur, pendidikan, pekerjaan terhadap pendapatan rumah tangga miskin di Desa Bebandem. Jurnal Ekonomi Pembangunan Universitas Udayana. 2 (4): 173-180.

Putri, A. N., Masy'ud, B., \& Gunawan, H. (2019). Persepsi masyarakat terhadap Taman Rusa Bumi Patra Indramayu, Jawa Barat. Jurnal Penelitian Hutan dan Konservasi Alam, 16(1): 13-24.

Sanudin, S. Awang., Sandono, R., \& Purwanto, R. H. (2016). Perkembangan hutan kemasyarakatan di Provinsi Lampung (progress of community forest in Lampung Province). Jurnal Manusia dan Lingkungan, 23(2): 276-283. 
Sugiyono. (2014). Memahami Penelitian Kualitatif. Buku. Alfabeta. Bandung.

Sugiyono. (2015). Statistik Untuk Penelitian. Buku. Alfabeta. Bandung.

Surati, Irawanti, S., Charity, D., Handoyo, Ariawan, K., Kurniawan, A. S., \& Mulyadin, R. M. (2019). Analisis mata pencaharian di lahan gambut: kasus Kabupaten Tanjung Jabung Barat. Jurnal Penelitian Sosial dan Ekonomi Kehutanan, 16(2): 81-93.

Tadesse, S. A., \& Teketay, D. (2017). Perceptions and attitudes of local people towards participatory forest management in Tarmaber District of North Shewa administrative zone, Ethiopia: the case of Wof-washa
Forests. Journal of Ecoogical Process, 6(17): 1-16.

Tampubolon, J., Cik A., \& Erta H. (2018). Persepsi masyarakat Desa Riding Kabupaten Ogan Komering Ilir terhadap upaya pencegahan kebakaran di lahan gambut. Jurnal Sylva, 7(2): 49-57.

Utami, A. (2016). Implementasi Program Pemberdayaan Masyarakat terhadap Pengelolaan Sarana Air Bersih berbasis Masyarakat. Skripsi. Bandar Lampung.

Wulandari, C., \& Inoue, M. (2018). The importance of social learning for the development of community based forest management in Indonesia: the case of community forestry in Lampung Province. Small-scale Forestry. 17(3): 361-376. 